\title{
Misexpression of a bHLH Gene, cNSCL1, Results in Abnormal Brain Development
}

\author{
CHUAN-MING LI, RUN-TAO YAN, and SHU-ZHEN WANG* \\ Department of Ophthalmology, University of Alabama at Birmingham School of Medicine, \\ Birmingham, Alabama
}

\section{Abstract}

NSCL1 is a basic helix-loop-helix transcription factor involved in the development of the nervous system. To elucidate its role in neurogenesis, we cloned chick NSCL1 ( $c N S C L 1)$ and examined its expression pattern and the effect of its misexpression on brain development. cNSCL1 was predominantly expressed during active neurogenesis. Double-labeling experiments showed that proliferating neuroblasts in the ventricular zone lacked $c N S C L 1$ expression and cells expressing cNSCLl were located just outside the ventricular zone. Retroviral misexpression of $c N S C L 1$ in chick embryos produced a brain with abnormal structure. While the forebrain of the embryonic day-12 (E12) brain appeared normal, the tectum was enlarged. The enlargement was likely due to an increase in cell proliferation, since more radioactivity was detected in this region of the brain after $\left[{ }^{3} \mathrm{H}\right]$ thymidine labeling at E9. The cerebellum, on the other hand, was reduced in size. Fewer cells were labeled with BrdU in the external granule layer (a secondary germinal layer required for cerebellum development) in experimental embryos than in the controls, suggesting that misexpression of cNSCL1 might interfere with cell proliferation in the external granular layer. Our data indicate that regulated expression of $c N S C L 1$ is required for normal brain development. They also imply that cNSCL1 might be involved in preventing some postmitotic cells from reentering the cell cycle during neurogenesis.

\section{Keywords}

bHLH; gene expression; neurogenesis; cell proliferation; differentiation; brain development

\section{INTRODUCTION}

The development of the vertebrate brain, which consists of numerous types of neurons and glia, requires the production of the correct number of cells at the correct times and in the correct places. Neurogenesis in the brain involves a phase of cell proliferation followed by cell differentiation and maturation. For example, in the chick optic tectum, cell proliferation is evident at embryonic day 4 (E4), increases to a peak level at E5-E6, declines thereafter, and ceases on E12 (Cowan et al., 1968). Yet at E12, cytoarchitectonic development is far from complete, but continues until at E16 (LaVail and Cowan, 1971). In the developing cortex, cell proliferation and cell differentiation take place in segregated areas. Proliferating neuroblasts are confined to the ventricular zone. After withdrawing from the cell cycle, postmitotic precursor cells migrate out from the ventricular zone and accumulate in the mantle zone, where

\footnotetext{
*Corresponding to: Shu-Zhen Wang, Department of Ophthalmology, University of Alabama at Birmingham School of Medicine, 700 South $18^{\text {th }}$ Street, Birmingham, AL 35233. E-mail: szwang@ vision.vsrc.uab.edu

Grant sponsor: Fight for Sight, Prevent Blindness America; Grant sponsor: National Eye Institute/NIH; Grant sponsor: University of Alabama at Birmingham Vision Science Research Center Pilot Grant; Grant sponsor: Research to Prevent Blindness; Grant numbers: PD98047 and EY11640.
} 
they differentiate and mature (Gray and Sanes, 1991; Ryder and Cepko, 1994). How these postmitotic cells are prevented from reentering the cell cycle erroneously, is not well understood.

Although most postmitotic cells in the brain enter a differentiation pathway, a particular group of cells from the rostral part of the rhombic lip migrate over the surface of the developing cerebellum, reenter the cell cycle, and form a secondary germinal layer-the external granule layer-which is responsible for the generation of the granule cells of the cerebellum (Hallonet et al., 1990; Hallonet and Le Douarin, 1993). In the chick, granule cell progenitors begin to migrate at E6, and form the secondary proliferative zone by E8 (Hanaway, 1967). Cell proliferation in the external granular layer is most active at E11 and stops at E18 (Margolis, 1969; Quesada and Genis-Galvez, 1983). It is not clear how the proliferating cells of the external granule layer are intrinsically different at the molecular level from those in the ventricular zone. Recently, Rex et al. (1998) have reported that progenitor cells in the ventricular zone express cSox 2 and cSox 3 , whereas progenitor cells in the external granular layer do not.

The control of the time of the transition from cell proliferation to cell differentiation in the nervous system is believed to involve many antagonistic factors and a proper balance of their actions is essential for neurogenesis to take place (Kageyama and Nakanishi, 1997). Recent studies have demonstrated that neural differentiation can be promoted by the expression of several basic helix-loop-helix (bHLH) genes (for review see Kageyama et al., 1997). Overexpression or misexpression of these genes often results in premature neural differentiation. The function and expression of these genes may be negatively regulated by Notch/Delta and a group of bHLH genes including Hes 1-5 and IdI-4 (Kageyama and Nakanishi, 1997).

Several other bHLH genes are also expressed during brain neurogenesis, but their function during brain development is largely unknown (Brown et al., 1992; Begley et al., 1992; McCormick et al., 1996; Sommer et al., 1996; Rostocil et al., 1997). One such gene lacking a "job description" is NSCLI (Begley et al., 1992), also called Henl (Brown et al., 1992) or Nhlhl (Good et al., 1997). Mammalian NSCL1 encodes a small protein of 133 amino acids (Brown et al., 1992; Begley et al., 1992). Expression of mammalian NSCL1 was assayed using Northern blotting and in situ hybridization and was found to be specific to neural tissues (Brown et al., 1992; Begley et al., 1992; Lipkowitz et al., 1992). In mouse embryos, NSCL1 mRNA is restricted to the subependymal layer and is not observed in the outer layers (Begley et al., 1992). Targeted deletion of NSCL2, a closely related gene, results in a disruption of the hypothalamic-pituitary axis and triggers adult-onset obesity in mice (Good et al., 1997). However, reports on the function of NSCL1 are limited.

We cloned chick NSCL1, termed $c N S C L 1$, and examined its expression and misexpression during the development of the chick brain. Like its mammalian counterpart, cNSCL1 was predominantly expressed in developing neural tissues. However, $c N S C L 1$ was only expressed after the cells became postmitotic and was not expressed in all domains of the developing brain. Retrovirally driven misexpression of $c N S C L 1$ strongly inhibited the development of the cerebellum, and yet resulted in an enlargement of the tectum. Our data imply that cNSCL1 is likely to be involved in postmitotic events during brain neurogenesis, probably by suppressing the expression of genes inappropriate to differentiation such as those involved in reentering the cell cycle. 


\section{RESULTS}

\section{Sequence of $c N S C L 1$}

Eight independent full-length cDNA clones of $c N S C L 1$ were isolated from embryonic chick brain using human $N S C L 1$ and mouse neuroD3 as probes. CNSCL1 encodes a 130-amino acid polypeptide with $80 \%$ overall identity to its human counterpart (Fig. 1). The bHLH region of the chick and human proteins is $98 \%$ identical (Fig. 1).

\section{Specific Expression of $c N S C L 1$ in Developing Neural Tissue}

Expression of $c N S C L 1$ was examined using RT-PCR of first strand cDNAs from embryonic brain and other tissues at various developmental stages. To show the rate of histogenesis, expression of chromokinesin, a gene specifically expressed in proliferating cells (Wang and Adler, 1995) was also assayed. Expression of ATP synthase subunit $C$ was used as a control for the relative amount of cDNA in each sample. All RT-PCR reactions for the three genes yielded bands of the expected size (data not shown). cNSCL1 yielded strong bands at embryonic day 8 (E8) and E12, indicating that the gene is transcribed at this time (Fig. 2). The intensity of the bands decreased from E8 to E12, and became barely detectable at E16. This pattern of expression was similar to that of chromokinesin, suggesting that $c N S C L 1$ might be expressed predominantly during the period of active histogenesis in the brain. Expression of $c N S C L 1$ was not detected in the heart, the kidney, or the liver, even at E8 when active histogenesis is taking place as reflected by the presence of chromokinesin mRNA (Fig. 2). RT-PCR reactions were independently repeated two times with cDNA samples standardized against two ubiquitously expressed genes, ribosomal protein S17 and ATP synthase subunit C; similar results were obtained each time (data not shown). Specific expression of $c N S C L 1$ in developing neural tissues was confirmed by in situ hybridization (see below).

\section{Spatial Pattern of $c N S C L 1$ Expression}

To eliminate the possibility of cross-hybridization to other bHLH family members, the 38 untranslated region of $c N S C L 1$ was used to make probes for in situ hybridization. Cells expressing $c N S C L 1$ were abundantly detected in all major regions of the developing brain: the myelencephalon, the mesencephalon, the diencephalon, and the telencephalon from E5 through E8 (Fig. 3A; data not shown). $c N S C L 1$ was also expressed in the spinal cord (Fig. 3B\&D). At E9 and thereafter, when cell proliferation in the ventricular zone subsides in most regions of the brain, the number of cells expressing $c N S C L 1$ decreased. Expression of $c N S C L 1$ became largely undetectable in the developing forebrain, tectum, and hindbrain at E15 (data not shown), except in the developing cerebellum. The cerebellum uses two separate germinal zones: the ventricular zone and the external granule layer, which is formed somewhat later. Expression of $c N S C L 1$ was seen in cells lining the external granule layer of the cerebellum (Fig. 3C\&E). The number of cells labeled appeared to be smaller at E19 than E15 (data not shown), suggesting that expression of $c N S C L 1$ was transient and confined to the period of active neurogenesis in this particular structure of the brain as well.

Although $c N S C L 1$ mRNA was detected in various regions of the developing nervous system, some sub-regions, or domains, were clearly negative. For example, the diencephalon was a chimera of $c N S C L 1$-expressing and $c N S C L 1$-nonexpressing domains (Fig. 3A). Additionally, the intensity of in situ hybridization signals appeared weaker in cells further away from the ventricular zone than those adjacent to it (Fig. 3F), implying that $c N S C L 1$ becomes downregulated as cells migrate toward the pia. $c N S C L 1$ mRNA was not detected in non-neural tissues in the head region (such as head mesenchyme, Fig. 3A), in the trunk region (Fig. 3B), or any other areas of the developing embryo (data not shown) providing additional evidence for its neural tissue specificity. The in situ data are consistent with the RT-PCR results showing neural tissue specificity and a down-regulation of $c N S C L 1$ expression during brain development. 


\section{cNSCL1 Expression Confined to Postmitotic Cells}

In the developing brain (Fig. 3A) and spinal cord (Fig. 3B\&D), cells expressing $c N S C L 1$ were concentrated in a distinct layer just outside the ventricular zone. To examine directly whether the proliferating neuroblasts in the ventricular zone express $c N S C L 1$, double-labeling experiments were carried out. Chick embryos were pulse-labeled with BrdU for four hours and subjected to analysis with in situ hybridization to detect $c N S C L 1$ mRNA and immunohistochemistry to visualize cells that had incorporated BrdU. The two labels did not overlap; cells expressing $c N S C L 1$ resided outside the territory defined by BrdU-positive cells (Fig. 3G). This demonstrates that cells positive for its expression were postmitotic and that the proliferating neuroblasts that compose the ventricular zone did not express $c N S C L 1$. Cells expressing $c N S C L 1$ lay immediately above the ventricular zone, indicating that as soon as postmitotic cells moved out of the ventricular zone, they started to express $c N S C L 1$. We also noted that domains lacking $c N S C L 1$ mRNA contained more BrdU-positive cells, and domains expressing $c N S C L 1$ had fewer cells labeled with BrdU in the developing diencephalon (Fig. 3H\&I).

\section{Altered Brain Structure in Embryos Misexpressing cNSCL1}

The replication-competent retrovirus, RCASBP(A) (Hughes et al., 1987; Fekete and Cepko, 1993) was used to misexpress $c N S C L 1$, or GFP as a control, in embryonic chick brain. The natural ability of the virus to spread in a population of proliferating cells enables viral-driven misexpression to occur in a wide range of tissues or cells infected by the virus. We have standardized microinjection procedure by placing the micropipette directly into the diencephalon below the optic cup and repeating microinjection of viral stock into the neural tube for a total of three times at three-hour intervals between stage 14 and stage 17 (E2). With this procedure, reproducible infection of the embryos was obtained. Immunohistological analysis of the brain with a specific antibody against P27, a viral protein, showed that at E8, viral infection was extensive in the developing forebrain and tectum (Fig. 4A; data not shown). Extensive viral infection was observed in all samples examined $(n=11)$ between E7 and E10. The developing cerebellum was also intensively infected (Fig. 4B) in all six cerebella examined. The developing brain stem, however, was poorly infected (Fig. 4B), and limited infection was observed in all cases $(n=7)$. This is because the initial viral inoculum mostly remained in the mesencephalon and telencephalon; spreading to the myelencephalon was limited (see Experimental Procedures). Head mesenchyme cells and neural crest derived tissues in the trunk and in the extremities were also infected by the virus. Unfortunately, widespread misexpression of $c N S C L 1$ in developing chick embryos causes the death of embryos halfway through gestation (Yan and Wang, unpublished data). Consequently, analysis of cNSCL1 misexpression was limited to embryos of E12 or younger.

Starting at E7, the tectum of embryos misexpressing $\operatorname{cNSCL1}(\mathrm{n}=67)$ appeared more protruding than in the controls $(n=64 ;$ Fig. 5A\&B). Among 134 embryos microinjected with the $c N S C L 1$ retroviruses (excluding those sacrificed for experiments), four survived to E12 and all four displayed abnormal brain development. The tecta were larger (Fig. 5D\&F) than those in the controls (Fig. 5C\&E), but no significant differences were observed in the sizes of the forebrains (Fig. 5C\&D; data not shown). The cerebellum, on the other hand, became very small in embryos infected with retroviruses expressing $c N S C L 1$ (Fig. 5C\&D), indicating that its development was strongly inhibited by misexpression of $c N S C L 1$. In embryos misexpressing $c N S C L 1$, the overall three-dimensional configuration of the brain was altered such that the laterals of the two hemispheres became closer to each other (Fig. 5C\&D). This alteration in the three-dimensional organization might be one of the underlying causes for the protrusion of the tectum that starts at E7. Alternatively, defective skull formation may be at fault (Yan and Wang, unpublished data). 
Comparison of anatomically equivalent regions showed that the tectum from embryos misexpressing $c N S C L 1$ was not thinner than that in embryos misexpressing GFP (data not shown). Thus the enlargement of the tectum was not simply the result of a reduction in the thickness of the tectum. Immunohistochemical analysis with an antibody against MAP2, a marker for neuronal differentiation, showed that the tecta not only were similar in thickness, but also appeared similar in terms of neural differentiation and lamination (Fig. 6A\&B). Considering the intensive viral infection of the tectum (Fig. 4A), its apparently normal differentiation and lamination suggest that misexpression of $c N S C L 1$ does not interfere with the timetable of tectum development. Detection for apoptotic cells in E7, E8, E9, and E10 brain cryosections showed no obvious differences in the number of cells labeled by the TUNEL method between embryos misexpressing $c N S C L 1$ and the controls (data not shown).

\section{Cell Proliferation Activities in the Tectum and the Hindbrain Regions}

The possibility that the enlargement of tectum resulted from a selective increase in cell proliferation in this structure was tested by pulse-labeling E7, E8, and E9 embryos with $\left[{ }^{3} \mathrm{H}\right]$ thymidine. Attempts to label older embryos were hampered by the fact that misexpression of $c N S C L 1$ is lethal and most embryos die early. Five hours after the addition of $\left[{ }^{3} \mathrm{H}\right]$ thymidine, embryos were harvested and the tectum and the hindbrain regions were dissected out. Incorporation of $\left[{ }^{3} \mathrm{H}\right]$ thymidine into DNA was measured. At E7 and E8, radioactivity in the tectum misexpressing $c N S C L 1$ was not different from the control misexpressing GFP (Fig. 7A). However, the tectum from E9 embryos misexpressing $c N S C L 1$ contained 59\% more radioactivity than the control, suggesting that more cells were proliferating (Fig. 7A). The overall radioactivity in the hindbrain region was not lower in $c N S C L 1$ embryos than in the control at E7, E8, and E9 (Fig. 7B).

We then investigated whether misexpression of $c N S C L 1$ in the developing cerebellum interfered with cell proliferation in its external granular layer. E9 embryos were pulse-labeled with BrdU for four hours, and the hindbrain region, including the cerebellum, was isolated, fixed, and analyzed for the incorporation of BrdU. Immunohistochemical analysis with antiBrdU antibody at anatomical equivalent locations showed that there were less positive cells in the external granular layer of cerebellum misexpressing $c N S C L 1$ (Fig. 8A) than in the control (Fig. 8B), while the ventricular layer seemed to have a comparable number of positive cells. The average number of BrdU-positive cells per view area was $224 \pm 34$ (mean \pm SD) in experimental samples and $499 \pm 79$ in the controls in the external granular layer at a centralcaudal region (Fig. 8C). Statistically, the difference is significant $(\mathrm{p}=0.00028)$. This reflects a 55\% reduction in the number of cells undergoing DNA replication during the pulse-labeling period in the external granular layer misexpressing $c N S C L 1$. Note that since the overall size of the cerebellum in embryos expressing $c N S C L 1$ was smaller than the control, the difference in number of proliferating cells in the entire external granular layer of the cerebellum should be even more dramatic than that per view area.

\section{DISCUSSION}

Expression of $c N S C L 1$, like its mammalian counterpart, appears to be restricted to developing neural tissues, as assayed by RT-PCR and in situ hybridization. In the developing brain, expression of $c N S C L 1$ was down-regulated and its mRNA was detected only during active neurogenesis including late-occurring histogenesis in the cerebellum (Duncan et al., 1997). Double-labeling experiments revealed that $c N S C L 1$ was expressed in postmitotic cells, and not in neuroblasts still in the cell cycle. This suggests that $c N S C L 1$ may be involved in guiding the unfolding of a proper gene expression program, promoting migration, or preventing postmitotic cells from reentering the cell cycle erroneously. The third scenario is favored by the observation that development of the cerebellum in embryos misexpressing $c N S C L 1$ was particularly retarded. 
The spatial/temporal pattern of $c N S C L 1$ expression during brain development resembles those of neuroD (Lee et al., 1995) and tenp, a novel gene transiently expressed in young postmitotic neurons (Yan and Wang, 1998a). However, unlike tenp, which has a rather uniform expression in all regions of the brain, $c N S C L 1$ expression showed sub-regional variations, suggesting that its expression is confined to certain types of young neurons. Expression of $c N S C L 1$ in the retina was found to be cell type-specific ( $\mathrm{Li}$ et al., 1999), while tenp is expressed only in precursor cells without noticeable differentiation (Yan and Wang, 1998a). These findings suggest that there is no direct relationship between tenp and $c N S C L 1$, despite their similar temporal and, to some extent, spatial patterns of expression.

Retrovirally driven misexpression of $c N S C L 1$ in the developing brain resulted in abnormal development. The tectum became enlarged, the cerebellum was so poorly developed that it appeared to be missing, and yet the forebrain had no gross change. The differential outcomes could not be simply attributed to differences in $C N S C L 1$ expression under natural conditions, since its mRNA was detected in all these regions. Examination of E7, E8, E9, and E10 brains for apoptotic cells with the TUNEL assay failed to detect significant differences between embryos misexpressing $c N S C L 1$ and the controls misexpressing GFP, suggesting that cell death may not be a major factor contributing to the alteration of brain structure observed with misexpression of $c N S C L 1$.

It is not likely that the small size of cerebellum was due to poor health or a developmental delay of infected embryos. First of all, embryos infected with the control retrovirus expressing GFP developed normally at both the gross and microscopic levels. Second, among the embryos misexpressing $c N S C L 1$, no differences were observed in terms of cellular differentiation and lamination of the tectum, which was heavily infected by retrovirus expressing $c N S C L 1$, arguing against a general delay in development. Third, the eyes of embryos misexpressing $c N S C L 1$ are greatly reduced in size, while their retinas adhere to the same timetable of differentiation as the controls (Li et al., 1999). Furthermore, RNase protection assay showed that the amount of translatable $c N S C L 1$ mRNA produced under the viral control is 1-3 fold of that of endogenous mRNA, indicating that the misexpression is not an over-expression (Li et al., 1999).

Cell proliferation activity in the ventricular zones of the tectum and the hindbrain regions was not decreased by $c N S C L 1$ misexpression, as indicated by the incorporation of $\left[{ }^{3} \mathrm{H}\right]$ thymidine. On the contrary, the tectum from E9, but not E7 or E8, cNSCL1 embryos contained more radioactivity than the controls, suggesting that there was a later-occurring increase in cell proliferation activity in the tectum of embryos misexpressing $c N S C L 1$. This late increase in cell proliferation is possibly secondary to the malformation of skull (Yan and Wang, unpublished data). The increased space and reduced pressure may trigger more cells to divide. Alternatively, intrinsic cellular properties may cause the tectum to behave differently from the cerebellum.

The opposite outcomes of $c N S C L 1$ misexpression between the tectum and cerebellum might be because histogenesis in the cerebellum is complicated by the involvement of the external granule layer, a secondary germinal zone derived from cells produced by the ventricular zone. It is possible that proliferating cells in the external granule layer are more sensitive than those in the ventricular zone to a signal from $c N S C L 1$ that may instruct them to exit from the cell cycle prematurely, or not to re-enter the cell cycle at all. As a result, cell proliferation in the external granule layer would be significantly reduced or diminished. Indeed, pulse-labeling experiments showed that the number of BrdU-labeled cells in the external granular layer was much less in E9 embryos misexpressing cNSCL1 than in controls. Since cell proliferation is mostly active in the external granular layer starting at E11 (Margolis, 1969), the absence, or significant reduction in the size, of the cerebellum at E12 likely resulted from a suppression of cell proliferation in the external granular layer. Furthermore, premature cessation of mitotic 
activity was observed in retinal neuroepithelium misexpressing $c N S C L 1$ (Li et al., 1999), arguing that $c N S C L 1$ has the ability to instruct certain proliferating retinoblasts to withdraw from the cell cycle prematurely. The hypothesis that $c N S C L 1$ is involved in preventing postmitotic cells from reentering the cell cycle is consistent with its expression in cells lying immediately outside of the ventricular zone.

The formation of the cerebellum involves not just the met- and myelencephalic vesicles. The mesencephalon, which gives rise to the optic tectum, also participates in the construction of the cerebellum by generating cells that eventually migrate into all the cellular layers of the rostral portion of the cerebellum (Hallonet et al., 1990). It is possible that misexpression of cNSCL1 interfered with the migration of mesencephalic cells into the cerebellum, resulting in more cells accumulating in the tectum and less cells in the cerebellum. This scenario may partially explain the size reduction of the cerebellum; it cannot, however, explain the reduction in cell proliferation in the external granular layer, which does not involve cells from the mesencephalic vesicle (Hallonet et al., 1990).

It should be mentioned that bHLH proteins can form heterodimers with one another. It is possible that the alterations in brain development in embryos misexpressing $c N S C L 1$ may have resulted from other bHLH proteins losing or changing their normal activities when they dimerized with the ectopically produced $c N S C L 1$ protein. Since different regions of the brain are likely to contain different bHLH proteins with varied affinity for $c N S C L 1$ protein, they may display variations in response to its ectopic production.

Gross abnormalities in brain development have not been observed with misexpression of three other members of the bHLH family. Embryos misexpressing neuroD in the same manner did not show obvious structural changes during brain development (our unpublished data) even though neuroD can convert some non-neuronal cell types into neurons (Lee et al., 1995; Yan and Wang, 1998b). Similarly, misexpression of two other bHLH genes, cNSCL3 and chick neurogenin2, did not produce visible changes in brain structure at the gross level (our unpublished data). Clearly, the action of $c N S C L 1$ is distinctive. Both the expression pattern and the dramatic results of $c N S C L 1$ misexpression on embryonic brain development suggest that the appropriate regulation of $c N S C L 1$ expression is very critical for proper development of the brain.

\section{EXPERIMENTAL PROCEDURES}

\section{Cloning of Chick NSCL1}

The coding region of human NSCL1 (Begley et al., 1992; Brown et al., 1992) was RT-PCR amplified from first strand cDNA synthesized with total RNA isolated from human retinoblastoma cell line Y79. The coding region of mouse neuroD3 (McCormick et al., 1996) was PCR amplified from mouse genomic DNA. After sequence verification, the cloned human NSCL1 and mouse neuroD3 fragments were independently used as probes to screen an E8 chick brain cDNA library (Yan and Wang, 1998a). Most of clones identified with NSCL1 probe carried inserts belonging to the $c N S C L$ subfamily (our unpublished data), and some of the clones identified with neuroD3 harbored inserts of $c N S C L 1$. A total of eight primary clones of $c N S C L 1$ were purified and they contained inserts of 2.2 to $2.5 \mathrm{~kb}$. The nucleotide sequence in and around the coding region was determined on both strands.

\section{RT-PCR}

A pair of primers, CCATGGTCAACTCGGAGCAGACAG and

CAGGCTGGGCGGCTCAGAC corresponding to the $5^{\prime}$ and $3^{\prime}$ end of the coding sequence of cNSCL1, respectively, were synthesized commercially and used in RT-PCR with first strand 
cDNA preparations collected previously (Yan and Wang, 1998a) and representing chick brain and non-neural tissues at different embryonic stages. PCR was performed in the presence of 1 $\mathrm{M}$ betaine and 5\% dimethyl sulfoxide for 30 cycles of amplification each at $95^{\circ} \mathrm{C}$ for one minute, $52^{\circ} \mathrm{C}$ for one minute, and $72^{\circ} \mathrm{C}$ for one minute. The primers and PCR conditions for chromokinesin and ATP synthase subunit $\mathrm{C}$ were previously described (Yan and Wang, 1998a). RT-PCR products were analyzed by agarose gel electrophoresis.

\section{In Situ Hybridization}

Fertilized, pathogen-free chicken eggs (White Leghorn) purchased from Spafas (Preston, Connecticut) were incubated in a Petersime Incubator (Gettysburg, Ohio). The entire head of young embryos $(<\mathrm{E} 7)$, the brain (E7-E12), or separated brain regions $(>E 12)$ were fixed with $4 \%$ paraformaldehyde, cryoprotected with $20 \%$ sucrose, and quick-frozen with liquid nitrogen. To avoid potential cross hybridization with other bHLH genes, the $3^{\prime}$ untranslated region of cNSCL1 was chosen as the template for antisense RNA probe synthesis. Plasmids were excised from positive $\lambda$ Uni-ZAP XR clones harboring full-length cDNA of approximately 2500 base pairs (bp), on which the coding region resides between nucleotide 453 and 845 . Digestion with EcoRI, which recognizes the $5^{\prime}$ cloning site and a site about $1500 \mathrm{bp}$ downstream, was used to rid the clone of the $5^{\prime}$ sequences, leaving $1000 \mathrm{bp} \mathrm{3'}$ untranslated region attached to the vector. T7 RNA polymerase was used to synthesize digoxigenin-labeled antisense RNA probes with the Genius Kit (Boehringer Mannheim) following the manufacturer's instructions. In situ hybridization was performed on cryosections of 8-10 $\mu \mathrm{m}$ as previously described (Wang and Adler, 1994).

\section{Generation of Retroviruses Expressing cNSCL1}

The entire coding region of chick $c N S C L 1$ was PCR amplified from a plasmid harboring its cDNA, and the PCR products were cloned into shuttle vector Cla12Nco (Hughes et al., 1987) at the Nco I site. A Cla I fragment containing $c N S C L 1$ along with the $5^{\prime}$ untranslated sequence of the $s r c$ oncogene was then inserted into provirus vector RCASBP(A) (Hughes et al., 1987). The presence of a splicing acceptor immediately upstream of the Cla I site enables virally driven $c N S C L 1$ expression in cells infected with the virus, which is replicationcompetent. Production of concentrated retrovirus stocks $\left(4-8 \times 10^{7} \mathrm{pfu} / \mathrm{ml}\right)$ was as previously described (Fekete and Cepko, 1993; Yan and Wang, 1998b). The control for microinjection and viral infection was a retrovirus expressing GFP described previously (Yan and Wang, 1998b).

\section{Microinjection of Retroviruses into Chick Embryos}

Eggs were incubated in a moist incubator and staged according to Hamburger and Hamilton (1951). Concentrated viral suspension $\left(4-8 \times 10^{7} \mathrm{pfu} / \mathrm{ml}\right)$ was microinjected into the neural tube at E2 (stage 14-17) with the injecting micropipette placed directly into the diencephalon just ventral to the optic cup (Yan and Wang, 1998b). To increase the viral infection rate, the microinjection procedure was repeated two more times at 3-hour intervals. During the initial injection, viral inoculum (visible due to the inclusion of a dye; Fekete and Cepko, 1993) distributed more or less evenly through the entire neural tube. For the two subsequent injections, spreading of the inoculum to the caudal region of the myelencephalon was limited because the neural tube can be only partially filled at these times to avoid killing the embryos.

\section{Immunohistochemical Analysis}

At stages as specified brains from embryos misexpressing either $c N S C L 1$ or GFP as control were fixed and processed the same way as for in situ hybridization. Standard methods were followed for immunohistochemical staining with ABC-peroxidase (Vector Laboratories) as described by the manufacturer. Monoclonal antibody against MAP2 (a, b, and c, diluted 200 
folds) was purchased from Sigma. Specific antibody against viral protein P27 (1 to 1000 dilutions) was purchased from Spafas. Monoclonal antibody against BrdU (1 to 50 dilutions) was obtained from the Developmental Studies Hybridoma Bank (University of Iowa).

\section{Detection of Apoptotic Cells}

The presence of apoptotic cells in cryosections of the developing brain was examined by the TUNEL method using the In Situ Cell Death Detection Kit (Boehringer Mannheim) following the manufacturer's instructions.

\section{In Vivo Incorporation of $\left[{ }^{3} \mathrm{H}\right]$ thymidine}

Incorporation of $\left[{ }^{3} \mathrm{H}\right]$ thymidine was used as an indicator of cell proliferation. After dilution in Hank's Balanced Salt Solution (HBSS), $\left[{ }^{3} \mathrm{H}\right]$ thymidine ( $10 \mu \mathrm{Ci}$ per embryo) was dropped onto each embryo at E7, E8, or E9. After five hours of incubation, different portions of the brain were dissected out and kept at $-20^{\circ} \mathrm{C}$. Tissue preparations for scintillation counting were based on a published method (Stein et al., 1994) with modifications. Essentially, phosphate saline solution $(100 \mu \mathrm{l})$ was added to each frozen portion without thawing. This was vortexed vigorously to break down the tissue and lyse the cells. Trichloroacetic acid (TCA) solution (1.4 $\mathrm{ml}$ of $10 \% \mathrm{v}: \mathrm{v})$ was then added and the tissue was incubated on ice for 10 minutes, followed by centrifugation at $600 \times \mathrm{g}$ for five minutes at $4^{\circ} \mathrm{C}$. The pellet was resuspended with $1.5 \mathrm{ml}$ of $10 \%$ TCA and left on ice for 10 minutes. DNA was pelleted by centrifugation as before. The DNA pellet was resuspended with $150 \mu \mathrm{l}$ of $10 \%$ SDS followed by addition of four to seven $\mathrm{ml}$ of scintillation fluid. Incorporation of $\left[{ }^{3} \mathrm{H}\right]$ thymidine was measured with an automated scintillation counter. Total CPM from eight to ten embryos were used to calculate the means and the standard deviations (SD), except E9 cNSCL1, which was calculated from four embryos due to the death of some of the embryos.

\section{Pulse-Labeling and BrdU Immunohistochemistry}

After dilution with HBSS, BrdU was dropped onto E7 (50 $\mu \mathrm{g} \mathrm{BrdU})$ and E9 (75 $\mu \mathrm{g} \mathrm{BrdU})$ chick embryos through a window in the shell. Four hours later, the brain of E7 embryos, or the hindbrain region (including the cerebellum) of E9 embryos, was dissected out, fixed, cryoprotected with sucrose, embedded with sucrose/OCT, and frozen with liquid nitrogen. Pretreatment of cryosections was essentially the same as for in situ hybridization, including proteinase $\mathrm{K}$ digestion, acetic anhydride blocking, and 50\% formamide denaturation. Prior to the addition of anti-BrdU antibody, sections were incubated with $0.25 \%$ triton X-100 (in PBS) for $30 \mathrm{~min}, \mathrm{PBST} / 4 \mathrm{~N} \mathrm{HCl}$ (1:1) for $1 \mathrm{hr}$, three washes with PBST, and a blocking step. Standard immunohistochemistry was followed with 3-amino 9-ehtyl carbazole (AEC) as the colorimetric substrate.

For double-labeling experiments, E7 brain cryosections were first subjected to in situ hybridization. After colorimetric reaction of alkaline phosphatase, the tissue sections were treated with PBS + Triton X-100 and PBST/4 N HCl, as described above, before incubation with monoclonal antibody against BrdU. Goat-anti-mouse IgG (TRITC-labeled, 1 to 50 dilutions) was used as the secondary antibody.

\section{REFERENCES}

Begley CG, Lipkowitz S, Gobel V, Mahon KA, Bertness V, Green AR, Gough NM, Kirsch IR. Molecular characterization of NSCL, a gene encoding a helix-loop-helix protein expressed in the developing nervous system. Proc Natl Acad Sci USA 1992;89:38-42. [PubMed: 1729708]

Brown L, Espinosa R, Le Beau MM, Siciliano MJ, Baer R. HEN1 and HEN2: a subgroup of basic helixloop-helix genes that are coexpressed in a human neuroblastoma. Proc Natl Acad Sci USA 1992;89:8492-8496. [PubMed: 1528853] 
Cowan WM, Martin AH, Wenger E. Mitotic patterns in the optic tectum of the chick during normal development and after early removal of the optic vesicle. J Exp Zool 1968;169:71-92. [PubMed: 5696645]

Duncan MK, Bordas L, Dicicco-Bloom E, Chada KK. Expression of the helix-loop-helix genes Id-1 and NSCL-1 during cerebellar development. Dev Dyn 1997;208:107-114. [PubMed: 8989525]

Fekete DM, Cepko CL. Replication-competent retroviral vectors encoding alkaline phosphatase reveal spatial restriction of viral gene expression/transduction in the chick embryo. Mol Cell Biol 1993;13:2604-2613. [PubMed: 8455633]

Good DJ, Porter FD, Mahon KA, Parlow AF, Westphal H, Kirsch IR. Hypogonadism and obesity in mice with a targeted deletion of the Nh1h2 gene. Nat Genet 1997;15:397-401. [PubMed: 9090387]

Gray GE, Sanes JR. Migratory paths and phenotypic choices of clonally related cells in the avian optic tectum. Neuron 1991;6:211-225. [PubMed: 1704243]

Hallonet ME, Le Douarin NM. Tracing neuroepithelial cells of the mesencephalic and metencephalic alar plates during cerebellar ontogeny in quail-chick chimaeras. Eur J Neurosci 1993;5:1145-1155. [PubMed: 8281319]

Hallonet ME, Teillet MA, Le Douarin NM. A new approach to the development of the cerebellum provided by the quail-chick marker system. Development 1990;108:19-31. [PubMed: 2351063]

Hamburger V, Hamilton HL. A series of normal stages in the development of the chick embryo. J Morphol 1951;88:49-92.

Hanaway J. Formation and differentiation of the external granule layer of the chick cerebellum. J Comp Neurol 1967;131:1-14. [PubMed: 6069500]

Hughes SH, Greenhouse JJ, Petropoulos CJ, Sutrave P. Adaptor plasmids simplify the insertion of foreign DNA into helper-independent retroviral vectors. J Virol 1987;61:3004-3012. [PubMed: 3041020]

Kageyama R, Ishibashi M, Takebayashi K, Tomita K. bHLH transcription factors and mammalian neuronal differentiation. Int J Biochem Cell Biol 1997;29:1389-1399. [PubMed: 9570134]

Kageyama R, Nakanishi S. Helix-loop-helix factors in growth and differentiation of the vertebrate nervous system. Curr Opin Genet Dev 1997;7:659-665. [PubMed: 9388783]

LaVail JH, Cowan WM. The development of the chick optic tectum. I. Normal morphology and cytoarchitectonic development. Brain Res 1971;28:391-419. [PubMed: 5111720]

Lee JE, Hollenberg SM, Snider L, Turner DL, Lipnick N, Weintraub H. Conversion of Xenopus ectoderm into neurons by NeuroD, a basic helix-loop-helix protein. Science 1995;268:836-844. [PubMed: 7754368]

Li C-M, Yan R-T, Wang S-Z. Misexpression of $c$ NSCLI disrupts retinal development. Mol Cell Neurosci. 1999in press

Lipkowitz S, Gobel V, Varterasian ML, Nakahara K, Tchorz K, Kirsch IR. A comparative structural characterization of the human NSCL-1 and NSCL-2 genes. Two basic helix-loop-helix genes expressed in the developing nervous system. J Biol Chem 1992;267:21065-21071. [PubMed: 1328219]

Margolis FL. DNA and DNA polymerase activity in chicken brain regions during ontogeny. J Neurochem 1969;16:447-456. [PubMed: 5795595]

McCormick MB, Tamimi RM, Snider L, Asakura A, Bergstrom D, Tapscott SJ. NeuroD2 and neuroD3: distinct expression patterns and transcriptional activation potentials within the neuroD gene family. Mol Cell Biol 1996;16:5792-5800. [PubMed: 8816493]

Quesada A, Genis-Galvez JM. Early development of the granule cells in the cerebellum of the chick embryo. J Morphol 1983;178:323-334. [PubMed: 6663627]

Rex M, Church R, Tointon K, Ichihashi RM, Mokhtar S, Uwanogho D, Sharpe PT, Scotting PJ. Granule cell development in the cerebellum is punctuated by changes in Sox gene expression. Brain Res Mol Brain Res 1998;55:28-34. [PubMed: 9645957]

Roztocil T, Matter-Sadzinski L, Alliod C, Ballivet M, Matter JM. NeuroM, a neural helix-loop-helix transcription factor, defines a new transition stage in neurogenesis. Development 1997;124:32633272. [PubMed: 9310321]

Ryder EF, Cepko CL. Migration patterns of clonally related granule cells and their progenitors in the developing chick cerebellum. Neuron 1994;12:1011-1028. [PubMed: 8185941] 
Sommer L, Ma Q, Anderson DJ. neurogenins, a novel family of atonal-related bHLH transcription factors, are putative mammalian neuronal determination genes that reveal progenitor cell heterogeneity in the developing CNS and PNS. Mol Cell Neurosci 1996;8:221-241. [PubMed: 9000438]

Stein, GS.; Stein, JL.; Lian, JB.; Last, TJ.; Owen, T.; McCabe, L. Synchronization of normal diploid and transformed mammalian cells. In: Cellis, JE., editor. Cell Biology, A Laboratory handbook. Academic Press; San Diego: 1994. p. 282-287.

Wang S-Z, Adler R. A developmentally regulated basic-leucine zipper-like gene and its expression in embryonic retina and lens. Proc Natl Acad Sci USA 1994;91:1351-1355. [PubMed: 8108415]

Wang S-Z, Adler R. Chromokinesin: a DNA-binding, kinesin-like nuclear protein. J Cell Biol 1995;128:761-768. [PubMed: 7876303]

Yan R-T, Wang S-Z. Identification and characterization of tenp, a gene transiently expressed before overt cell differentiation during neurogenesis. J Neurobiol 1998a;34:319-328. [PubMed: 9514522]

Yan R-T, Wang S-Z. neuroD induces photoreceptor cell overproduction in vivo and de novo generation in vitro. J Neurobiol 1998b;36:485-496. [PubMed: 9740021] 


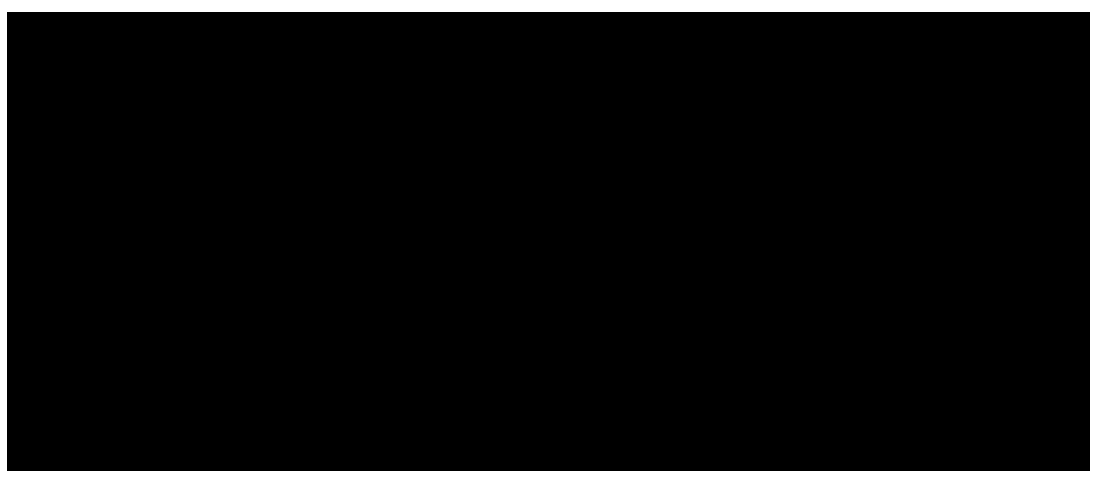

Fig. 1.

Primary structure of cNSCL1. The deduced amino acid sequence of $c N S C L 1$ is $80 \%$ identical (indicated by vertical lines) to human NSCL1 over the entire sequence and $98 \%$ identical in the bHLH region. The domains of the bHLH region are marked. Two gaps, represented by dots, were introduced to maximize homology. The Gen-Bank accession number for chick cNSCL1 is AF086757. 

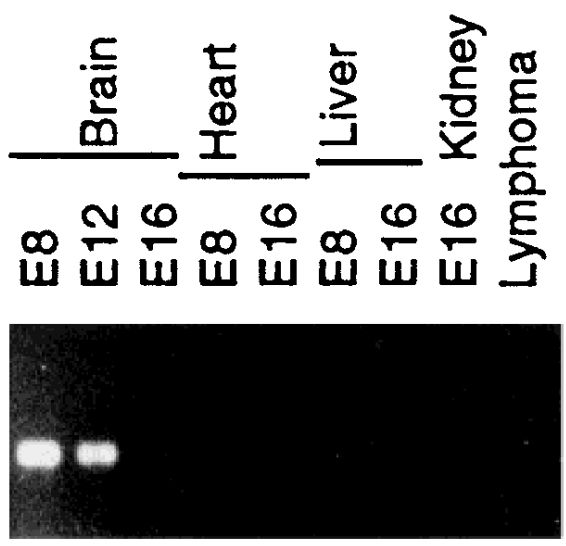

\section{CNSCL1}

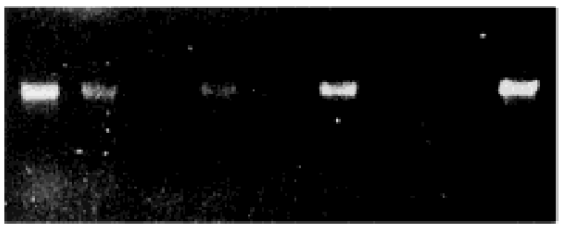

CHK

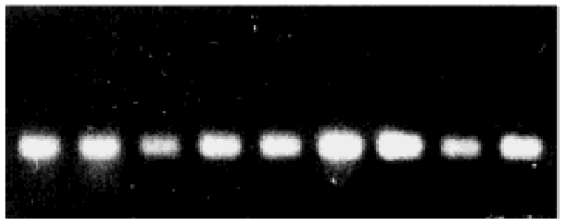

\section{ATP \\ synthase \\ subunit $\mathrm{C}$}

Fig. 2.

Expression of cNSCL1 in embryonic chick tissues analyzed by RT-PCR. Like chromokinesin (CHK), which is down-regulated during brain development, cNSCL1 mRNA was detected in the brain at E8 and E12, but not at E16. Unlike chromokinesin, $c N S C L 1$ was not expressed in E8 heart, E8 liver, or chick lymphoma cell line 2112 (obtained from ATCC), indicating those non-neural tissues and cells lacked $c N S C L 1$ mRNA. RT-PCR for ATP synthase subunit C illustrates the relative amount of cDNA in each sample. 

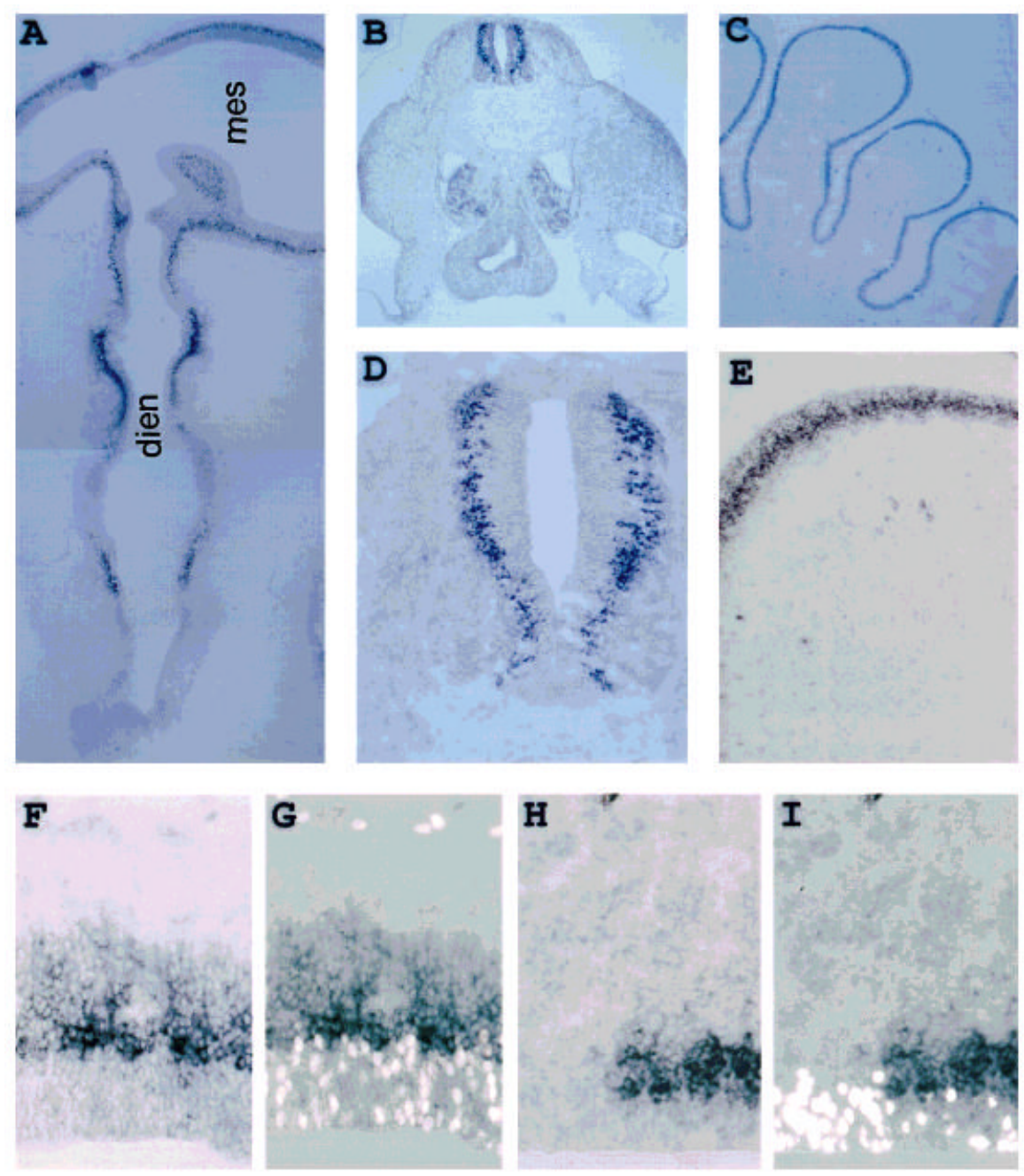

Fig. 3.

Expression of $c N S C L 1$ examined by in situ hybridization. At E6, cNSCL1 mRNA was detected in the mesencephalon (mes) and the diencephalon (dien) on a cranial section of the head (A), and in the spinal cord on a cross section of the body ( $\mathbf{B}$ and $\mathbf{D}$; D is a higher magnification of B). In E15 brain, cNSCL1 mRNA was largely concentrated in the cerebellum (C and E; E is a higher magnification of $\mathrm{C}$ ). In double-labeling experiments, cNSCL1 mRNA signals and BrdU signals did not overlap (F and G, E7 mesencephalon; H and I, E7 diencephalon; BrdU added four hours before tissue fixation on E7). F and $\mathrm{H}$ show the view for cNSCL1 mRNA only while $\mathrm{G}$ and I show simultaneous views for both labels. Magnifications: A-C, $10 \times$; D\&E, 50x; F-I, 100×. 

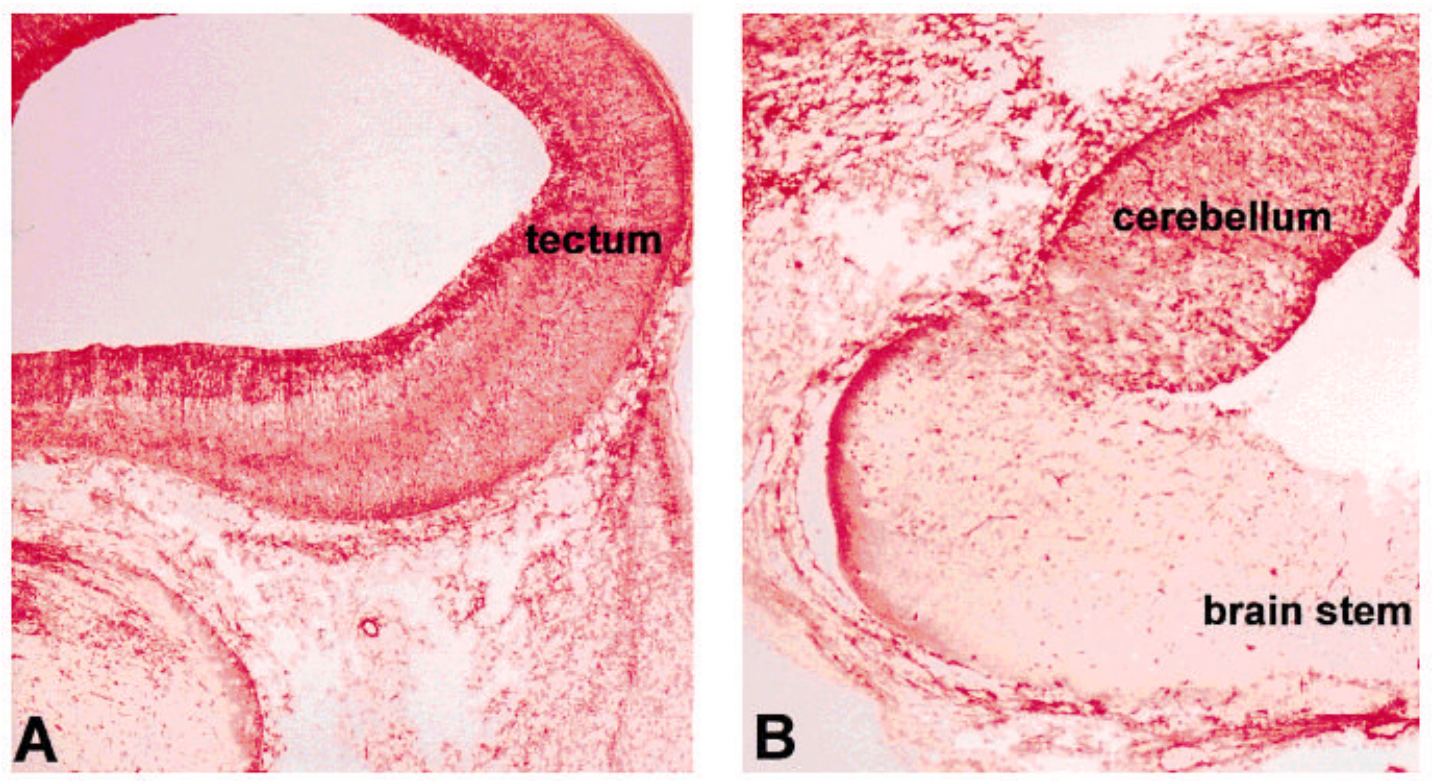

Fig. 4.

Retroviral infection of the tectum, the cerebellum, and the brain stem. Specific antibody against a viral protein, $\mathrm{P} 27$, was used to immunostain E8 brain microinjected with retrovirus expressing cNSCL1 on E2 (stage 14-17). The tectum and the cerebellum were extensively infected, indicated by the red colored immuno-positive signals. Infection of the brain stem was sparse. 


\section{GFP}
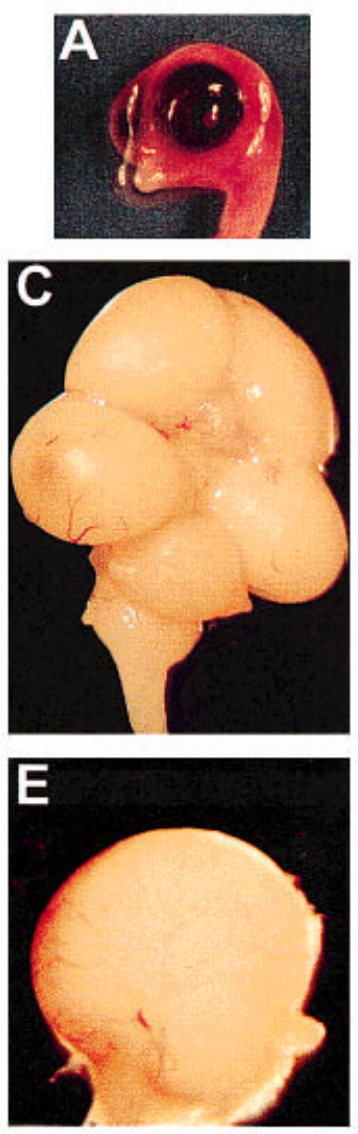

\section{cNSCL1}
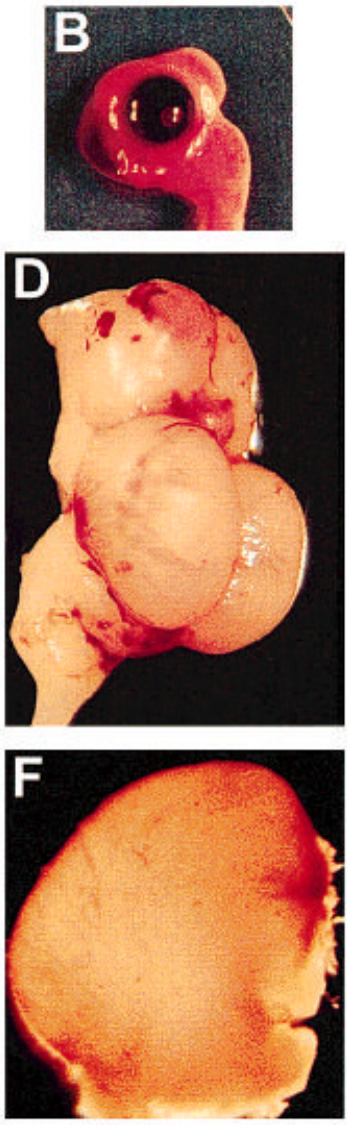

Fig. 5.

Abnormal brain development associated with $c N S C L 1$ misexpression. At E9, the embryo misexpressing $c N S C L 1$ (B) had a protruding tectum compared to the control misexpressing GFP (A). At E12, the brain of the experimental embryo (D) had a radically altered structure: the tectum was enlarged and the cerebellum was reduced, compared to the control $(\mathbf{C})$. When dissected out at E12, enlargement of the tectum in embryos misexpressing $\operatorname{NSCL1}$ (F) became clearly visible, compared to the control misexpressing GFP (E; lateral facing up and midline facing down; posterior to the left and anterior to the right). Microinjection of the retrovirus into the neural tube was carried out at E2 (stage 14-17). 

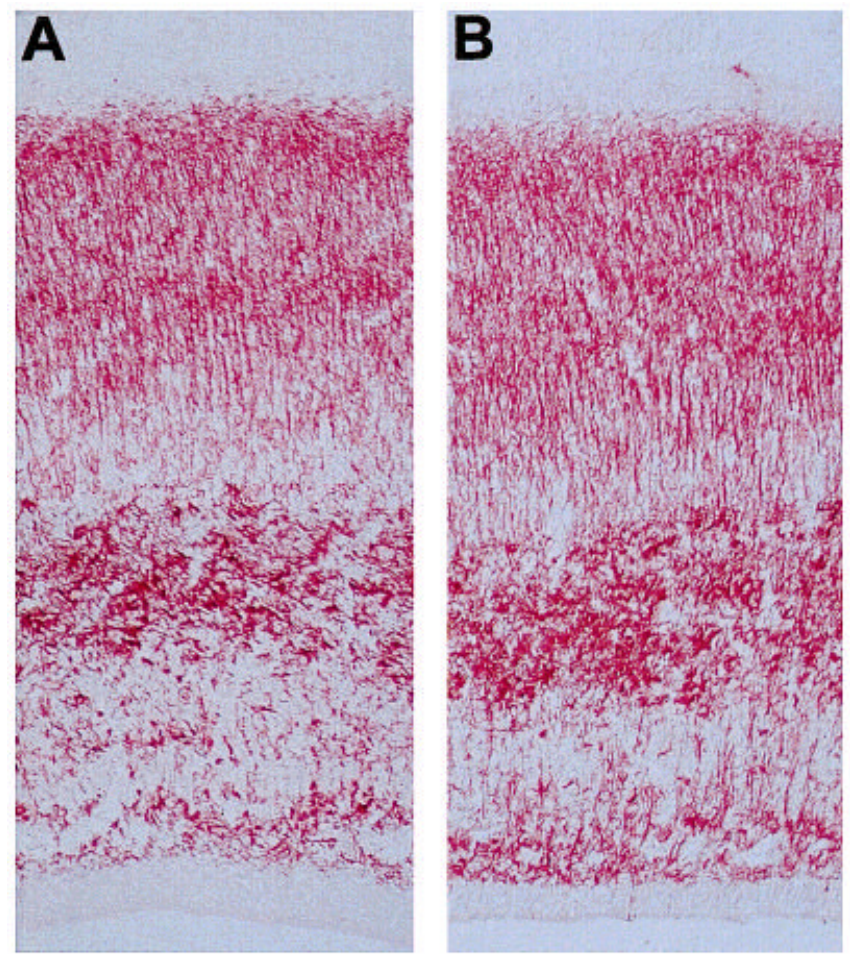

Fig. 6.

Expression of MAP2 in the tectum. Immunostaining of cryosections of E9 tecta with antibody against MAP2, a neural differentiation marker, showed no significant difference between embryos misexpressing GFP (A) and $c N S C L 1$ (B). Microinjection of the retrovirus into the neural tube was carried out at E2 (stage 14-17). 


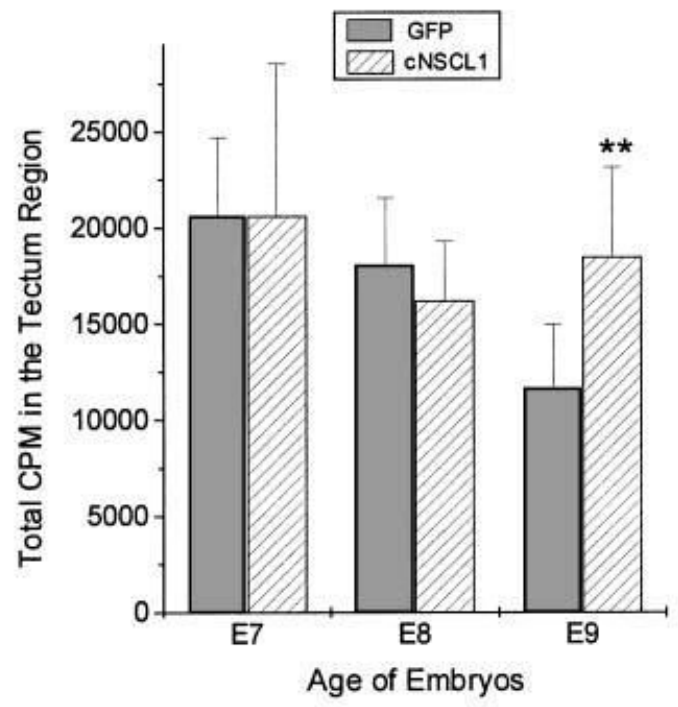

B

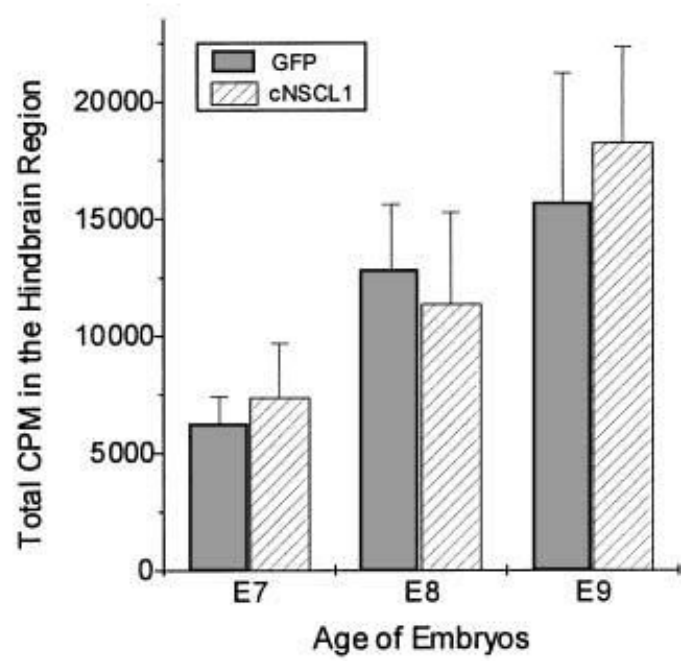

Fig. 7.

Incorporation of $\left[{ }^{3} \mathrm{H}\right]$ thymidine (mean $\pm \mathrm{SD}$ ). Total $\mathrm{CPM}$ of ${ }^{3} \mathrm{H}$ in the tectum $(\mathbf{A})$ and hindbrain (B) regions was measured in embryos misexpressing $c N S C L 1$, or GFP as control. Statistically significant difference $(\mathrm{p}<0.01)$ is indicated by **. Microinjection of the retrovirus into the neural tube was carried out at E2 (stage 14-17). 

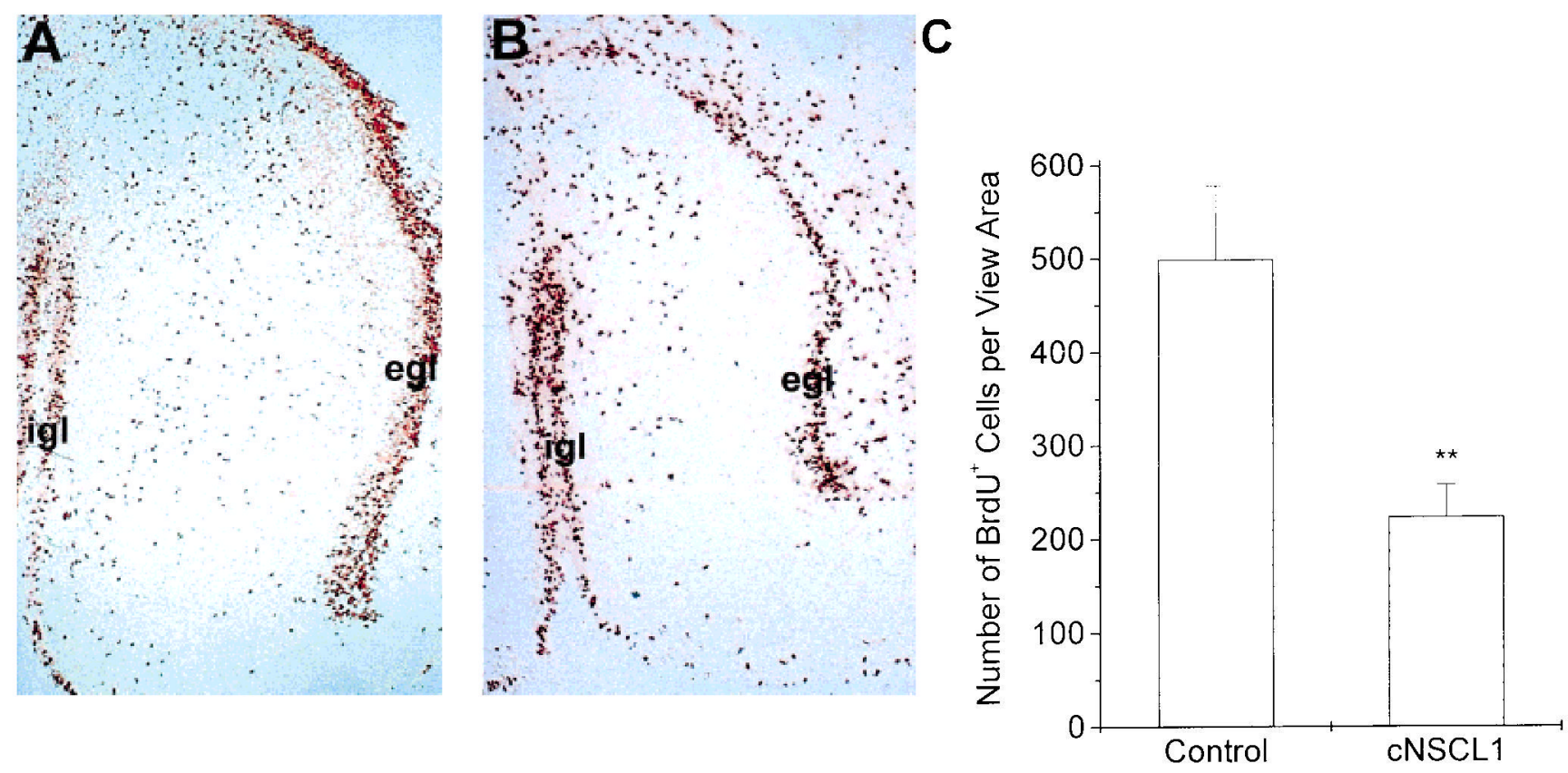

Fig. 8.

BrdU incorporation in E9 cerebellum. The external granular layer (egl) in the control (A) appeared to contain more BrdU-positive cells than the egl of embryos misexpressing cNSCL1 (B). The number of BrdU-positive cells in the ventricular zone, or the internal granular layer (igl), appeared comparable. Shown are cross sections of the rostral cerebella. (C) The number of BrdU-positive cells was counted in the central-caudal region from the three cNSCL1-expressing cerebella and three controls (each with three view areas counted). The average number of BrdU-positive cells per view area (with a 20× objective) in the $c N S C L 1$ expressing cerebella is significantly lower than that in the control $(\mathrm{p}<0.01)$, indicated by **. Data are presented as mean \pm SD. Microinjection of the retrovirus into the neural tube was carried out at E2 (stage 14-17) and BrdU was added four hours before fixation on E9. 